\title{
Enterprise Quality Credit Evaluation Based on Grey Correlation Analysis and TOPSIS Method
}

\author{
Tiedan Wang ${ }^{1}$, Jinjin Wang ${ }^{1}$, Dinghong Peng ${ }^{1,2}$ \\ ${ }^{1}$ Quality Development Institute of Kunming University of Science and Technology, Yunnan Province, China \\ ${ }^{2}$ School of Management, Harbin University of Science and Technology, Heilongjiang Province, China \\ mowjj@126.com
}

\begin{abstract}
Evaluate the enterprise quality credit with the method of grey correlation analysis and TOPSIS. Determine the main evaluation indicators of enterprise quality credit according to the quality credit definition proposed by GAQSIQ. Introduce the grey correlation analysis and TOPSIS method to the evaluation of the built indexes, resulting quality credit score of every enterprise, while ranking their quality credit level more accurately.
\end{abstract} TOPSIS

Index Terms - Enterprise Quality Credit, Grey Correlation,

\section{Introduction}

In recent years Chinese enterprises have experienced unprecedented crisis of quality credit. The quality credit is gradually put onto the cusp as a crucial social issue. Some companies collapse instantly owing to their terrible quality credit while others struggle to survive in this battle. In order to strengthen the internal and external regulatory efficiency of the enterprises, comprehensively improve the quality of products, reduce the safety risk in some areas, and improve people's satisfaction at the same time, to improve credit system construction and establish a scientific and reasonable credit evaluation system is the current urgent need in our country.

A lot of domestic scholars have already done some researches on quality credit evaluation. SUN[1] and LIU[2] have used the analytic hierarchy process (AHP) to build enterprise quality credit evaluation system, with conducting a comprehensive inspection and assessment on the enterprise internal quality management and product quality in accordance with the enterprise quality credit rating classification regulation. The classical MCDM method technique for order preference by similarity to ideal solution (TOPSIS) was used by ZHU[3] to evaluate the credit quality of 8 air-conditioning enterprises in China market. However, AHP, which is consisted of more qualitative ingredient, needs too many large amounts of data statistics and weights to easily determine. TOPSIS can't reflect the difference between internal factors' change trend and the ideal solution well.

Some scholars have tried to combine TOPSIS with grey correlation analysis so that the combination can more accurately describe the integration degree of alternative and ideal schemes, and used to compare the superiority of alternative schemes [4-6]. Now this paper attempts to use the combination in enterprise quality credit evaluation with a built system of quality credit evaluation criterion, aiming to rank the enterprise quality credit level in the same industry.

\section{The Determination of Enterprise Quality Credit Evaluation Indicators}

\subsection{Quality credit definition}

In 2006, the General Administration of Quality Supervision, Inspection and Quarantine (GAQSIQ) of China put forward the concept of credit quality for the first time [7], it proposes that credit quality is enterprise's capacity and performance of complying with laws as well as the commitment to its product quality.

\subsection{The determination of enterprise quality credit evaluation indicators}

According to the current situation and the typical characteristics of credit quality get from the concept, following the indicators' selection principle of independence, comprehensiveness, quantifiable at the same time, the paper selects 5 main indicators as follows, production quality level(PCL), quality assurance ability(QAA), reputation accumulation(RA), customer satisfaction(CS), and enterprise foundation credit(EFC).

Product quality level mainly includes the check rate, qualified rate and certification situation. As the representive of an enterprise, product quality directly affects the company's reputation. Qualified rate reflects product good or not, while certification situation is the basic guarantee of product.

Quality assurance ability reflects the enterprise's keeping capacity for its own quality, quality improvement, management. When it comes to some quality crisis, the enterprise can stand up to take responsibility and solve the problem.

Reputation accumulation is consisted by collect ability, ensuring extent, rewards amount and so on. It is accumulated by years' efforts, the track of enterprises' sustainable development.

Customer satisfaction is the evaluation given to the purchased product or service by customers and markets on the basis of their needs, preferences, and expectations. Because quality credit is concerned with contract with customers, customer satisfaction for quality credit evaluation is indispensible.

Enterprise foundation credit includes quality certification, adopted standards, and technical ability that can influence the quality of manufacture, management and eventually product.

\section{The Establishment of the Evaluation Model}

According to the characteristics of the evaluation 
indicators, and the purpose of the evaluation, the paper uses the improved TOPSIS model by grey correlation analysis to evaluate. The quality credit scoring process using grey correlation analysis and TOPSIS method is as follows:

Step 1: build index matrix

Assume there are $m$ enterprises to be evaluated and each of them has $\mathrm{n}$ indicators, and the corresponding index is $x_{i j}(i=1,2, \cdots, \mathrm{m} ; \mathrm{j}=1,2, \cdots, \mathrm{n})$, then the index matrix can be dominated by $X=\left(x_{i j}\right)_{m \times n}$

$$
R=\left[\begin{array}{ccc}
x_{11} & \cdots \cdots & x_{1 n} \\
\vdots & \cdots \cdots & \vdots \\
x_{m 1} & \cdots \cdots & x_{m n}
\end{array}\right]
$$

Step 2: normalize the index matrix

On account of the differences among the property and unit from different indicators, it is needed to normalize the index matrix as (2). Let $X^{*}=\left(x_{i j}^{*}\right)_{m \times n}$ express the dimensionless index matrix.

$$
x_{i j}^{*}=x_{i j} /\left(\sum_{i=1}^{m}\left(x_{i j}\right)^{2}\right)^{1 / 2}
$$

Step 3: determine the index weight

Entropy method is used to determine the weight of every indicator [8]. According to the definition of entropy, the entropy value of $j_{t h}$ indicator can be expressed as $b_{j}$.

$$
\begin{aligned}
& b_{j}=-\frac{1}{\ln m} \sum_{i=1}^{m} a_{i j} \ln a_{i j} \\
& a_{i j}=x_{i j}^{*} / \sum_{i=1}^{m} x_{i j}^{*}
\end{aligned}
$$

Where $a_{i j}$ represents the weight of $j_{t h}$ indicator of the $i_{t h}$ enterprise, so the entropy weight of $j_{t h}$ indicator is

$$
v_{j}=\left(1-b_{j}\right) / \sum_{j=1}^{n}\left(1-b_{j}\right)
$$

The vector of index weight is

$$
V=\left(v_{1}, v_{2}, \cdots, v_{n}\right)^{T}
$$

Step 4: normalize the index weight matrix

Multiply the normalized index matrix with the vector of index weight, it comes out the normalized matrix Y:

$$
Y=\left(y_{i j}\right)_{m \times n}=\left(v_{j} x_{i j}\right)_{m \times n}
$$

Step 5: determine PIS (Positive Ideal Solution) and NIS (Negative Ideal Solution)

$$
Y_{0}^{+}=\left(y_{1}^{+}, y_{2}^{+}, \cdots, y_{m}^{+}\right)=\left\{\begin{array}{l}
\max \left(y_{i j}\right), j \in J^{+} \\
\min \left(y_{i j}\right), j \in J^{-}
\end{array}, j=1,2, \cdots, n\right.
$$

$$
Y_{0}^{-}=\left(y_{1}^{-}, y_{2}^{-}, \cdots, y_{m}^{-}\right)=\left\{\begin{array}{l}
\min \left(y_{i j}\right), j \in J^{+} \\
\max \left(y_{i j}\right), j \in J^{-}
\end{array}, j=1,2, \cdots, n\right.
$$

Where $J^{+}$is the set of profit-oriented indicators and $J^{-}$is the set of cost-oriented indicators [9].

Step 6: calculate the Euclidean distance from each enterprise to PIS and NIS [10].

$$
\begin{aligned}
& D_{i}^{+}=\sqrt{\sum_{j=1}^{n}\left(y_{i j}-y_{j}^{+}\right)^{2}}, i=1,2, \cdots, m \\
& D_{i}^{-}=\sqrt{\sum_{j=1}^{n}\left(y_{i j}-y_{j}^{-}\right)^{2}}, i=1,2, \cdots, m
\end{aligned}
$$

Where $D_{i}^{+}$and $D_{i}^{-}$respectively represent the distance of the $i_{t h}$ enterprise from PIS and NIS.

Step 7: calculate grey correction degree

Based on the normalized matrix Y, the grey correction degree of the $i_{t h}$ enterprise to the $j_{t h}$ indicator of PIS and NIS are [11]:

$$
\begin{aligned}
s_{i j}^{+} & =\frac{\min _{i} \min _{j}\left|y_{j}^{+}-y_{i j}\right|+\rho \max _{i} \max _{j}\left|y_{j}^{+}-y_{i j}\right|}{\left|y_{j}^{+}-y_{i j}\right|+\rho \max _{i} \max _{j}\left|y_{j}^{+}-y_{i j}\right|} \\
s_{i j}^{-} & =\frac{\min _{i} \min _{j}\left|y_{j}^{-}-y_{i j}\right|+\rho \max _{i} \max _{j}\left|y_{j}^{-}-y_{i j}\right|}{\left|y_{j}^{-}-y_{i j}\right|+\rho \max _{i} \max _{j}\left|y_{j}^{-}-y_{i j}\right|}
\end{aligned}
$$

Normal range of $\rho$ is in the interval $[0,1]$. According to experience, let $\rho=0.5$ in this access. Relational matrix can be expressed as:

$$
W^{+}=\left[\begin{array}{cccc}
s_{11}^{+} & s_{12}^{+} & \ldots & s_{1 n}^{+} \\
s_{21}^{+} & s_{22}^{+} & \ldots & s_{2 n}^{+} \\
\vdots & \vdots & \ddots & \vdots \\
s_{m 1}^{+} & s_{m 2}^{+} & \ldots & s_{m n}^{+}
\end{array}\right]
$$

$$
W^{-}=\left[\begin{array}{cccc}
s_{11}^{-} & s_{12}^{-} & \cdots & s_{1 n}^{-} \\
s_{21}^{-} & s_{22}^{-} & \cdots & s_{2 n}^{-} \\
\vdots & \vdots & \ddots & \vdots \\
s_{m 1}^{-} & s_{m 2}^{-} & \cdots & s_{m n}^{-}
\end{array}\right]
$$

The grey correction degree of the $i_{t h}$ enterprise to PIS and NIS are:

$$
W_{i}^{+}=\frac{1}{n} \sum_{j=1}^{n} s_{i j}^{+}, i=1,2, \cdots, m
$$




$$
W_{i}^{-}=\frac{1}{n} \sum_{j=1}^{n} s_{i j}^{-}, i=1,2, \cdots, m
$$

Step 8: calculate the relative closeness, realize the best rank of $m$ enterprises.

Dimensionless Euclidean distance and grey correction degree are respectively represented as $d_{i}^{+}, d_{i}^{-}, w_{i}^{+}$and $w_{i}^{-}$.

$$
\begin{aligned}
& T_{i}^{+}=e_{1} d_{i}^{-}+e_{2} w_{i}^{+}, i=1,2, \cdots, m \\
& T_{i}^{-}=e_{1} d_{i}^{+}+e_{2} w_{i}^{-}, i=1,2, \cdots, m
\end{aligned}
$$

Where $e_{1}$ and $e_{2}$ reflect the degree of decision-makers' preference, and $e_{1}+e_{2}=1$. Where $T_{i}^{+}$and $T_{i}^{-}$respectively represents the approaching degree from the $i_{t h}$ enterprise to PIS and NIS.

$$
\delta_{i}=\frac{T_{i}^{+}}{T_{i}^{+}+T_{i}^{-}}, i=1,2, \cdots, m
$$

Where $\delta_{i}$ is called quality credit score in this study representing the relative approaching degree of the $i_{t h}$ enterprise to PIS and NIS.

Step 9: rank the enterprises according to their quality credit scores.

According to the result we get from (20), rank the enterprises by their quality credit scores. When $\delta_{i}$ is bigger, its enterprise is closer to the positive ideal, and vice versa.

\section{Experiment}

In this section, a set of quality credit evaluation data of car manufacture enterprises is used to get their quality credit scores, and then rank the level of their quality credit. We obtained the quality credit evaluation data of 11 enterprises from a quality credit evaluator. Their points are from 1 to 100 .

TABLE I Original Data

\begin{tabular}{|c|c|c|c|c|c|}
\hline enterprise & PQL & QAA & RA & CS & EFC \\
\hline 1 & 90 & 100 & 75 & 40 & 100 \\
\hline 2 & 90 & 100 & 72 & 40 & 100 \\
\hline 3 & 90 & 100 & 70 & 40 & 100 \\
\hline 4 & 92 & 100 & 73 & 40 & 100 \\
\hline 5 & 94 & 100 & 68 & 40 & 100 \\
\hline 6 & 93 & 100 & 67 & 40 & 100 \\
\hline 7 & 92 & 100 & 65 & 40 & 100 \\
\hline 8 & 90 & 100 & 63 & 40 & 100 \\
\hline 9 & 91 & 100 & 62 & 40 & 100 \\
\hline 10 & 85 & 99 & 60 & 35 & 100 \\
\hline 11 & 83 & 97 & 55 & 35 & 100 \\
\hline
\end{tabular}

According to entropy method from (2) to (6), the weight of every indicator can be calculated as tab 2 .

TABLE II Index Weights

\begin{tabular}{|c|c|c|c|c|c|}
\hline & PQL & QAA & RA & CS & EFC \\
\hline weight & 0.2001 & 0.2003 & 0.1993 & 0.2000 & 0.2003 \\
\hline
\end{tabular}

After we got weights in tab 2, according to (7), the normalized matrix Y can be expressed as below.

$\left[\begin{array}{lllll}0.0603069 & 0.0606054 & 0.0676593 & 0.0616218 & 0.0603904 \\ 0.0603069 & 0.0606054 & 0.0649529 & 0.0616218 & 0.0603904 \\ 0.0603069 & 0.0606054 & 0.0631487 & 0.0616218 & 0.0603904 \\ 0.0616470 & 0.0606054 & 0.0658551 & 0.0616218 & 0.0603904 \\ 0.0629872 & 0.0606054 & 0.0613444 & 0.0616218 & 0.0603904 \\ 0.0623171 & 0.0606054 & 0.0604423 & 0.0616218 & 0.0603904 \\ 0.0616470 & 0.0606054 & 0.0586381 & 0.0616218 & 0.0603904 \\ 0.0603069 & 0.0606054 & 0.0568338 & 0.0616218 & 0.0603904 \\ 0.0609769 & 0.0606054 & 0.0559317 & 0.0616218 & 0.0603904 \\ 0.0569565 & 0.0599994 & 0.0541274 & 0.0539191 & 0.0603904 \\ 0.0556163 & 0.0587873 & 0.0496168 & 0.0539191 & 0.0603904\end{array}\right]$

According to (8) and (9), we can get the PIS $Y_{0}^{+}$and NIS $Y_{0}^{-}$.

$$
\begin{aligned}
& Y_{0}^{+}=(0.0629872,0.0606054,0.0676593,0.0616218,0.0603904) \\
& Y_{0}^{-}=(0.0556163,0.0587873,0.0496168,0.0539191,0.0603904)
\end{aligned}
$$

Then according to (10) and (11), we can calculate the Euclidean distance, and get the grey correlation degree from (12) to (13).

TABLE III Euclidean distance and grey correlation degree from the $i_{t h}$ enterprise to PIS and NIS

\begin{tabular}{|c|c|c|c|c|}
\hline Enterprise & $\begin{array}{c}\text { Euclidean } \\
\text { distance to } \\
\text { PIS }\end{array}$ & $\begin{array}{c}\text { Euclidean } \\
\text { distance to } \\
\text { NIS }\end{array}$ & $\begin{array}{c}\text { grey } \\
\text { correlation } \\
\text { degree to PIS }\end{array}$ & $\begin{array}{c}\text { grey } \\
\text { correlation } \\
\text { degree to NIS }\end{array}$ \\
\hline 1 & 0.00268 & 0.020253 & 0.7042139 & 0.7309239 \\
\hline 2 & 0.003809 & 0.017884 & 0.7048251 & 0.7317783 \\
\hline 3 & 0.005247 & 0.016363 & 0.7052358 & 0.7323534 \\
\hline 4 & 0.002248 & 0.019044 & 0.7046207 & 0.7314924 \\
\hline 5 & 0.006315 & 0.015953 & 0.7056491 & 0.7329330 \\
\hline 6 & 0.007248 & 0.014991 & 0.7058568 & 0.7332244 \\
\hline 7 & 0.00912 & 0.013431 & 0.7062741 & 0.7338108 \\
\hline 8 & 0.011152 & 0.011693 & 0.7066941 & 0.7344018 \\
\hline 9 & 0.011899 & 0.011457 & 0.7069051 & 0.7346990 \\
\hline 10 & 0.016709 & 0.004859 & 0.7095546 & 0.7378294 \\
\hline 11 & 0.021036 & 0 & 0.7110889 & 0.7309239 \\
\hline
\end{tabular}

On the base of resulting the Euclidean distance and grey correlation degree, let $e_{1}=e_{2}=0.5$ in terms of the approaching 
degree from the $i_{\text {th }}$ enterprise to PIS and NIS that show in (18) and (19).

TABLE IV Closeness between the $i_{\text {th }}$ enterprise and PIS or NIS

\begin{tabular}{|c|c|c|}
\hline Enterprise & $\begin{array}{c}\text { Closeness between the } \\
i_{t h} \text { enterprise and PIS }\end{array}$ & $\begin{array}{c}\text { Closeness between the } \\
i_{t h} \text { enterprise and NIS }\end{array}$ \\
\hline 1 & 0.362233445 & 0.366802 \\
\hline 2 & 0.361354551 & 0.367794 \\
\hline 3 & 0.360799408 & 0.3688 \\
\hline 4 & 0.36183236 & 0.36687 \\
\hline 5 & 0.360801075 & 0.369624 \\
\hline 6 & 0.360423905 & 0.370236 \\
\hline 7 & 0.359852562 & 0.371465 \\
\hline 8 & 0.359193562 & 0.372777 \\
\hline 9 & 0.359181069 & 0.373299 \\
\hline 10 & 0.357206814 & 0.377269 \\
\hline 11 & 0.355544463 & 0.37598 \\
\hline
\end{tabular}

TABLE V Evaluation result

\begin{tabular}{|c|cccccc|}
\hline Enterprise & 1 & 2 & 3 & 4 & 5 & 6 \\
\hline $\begin{array}{c}\text { approaching } \\
\text { degree }\end{array}$ & 0.4969 & 0.4956 & 0.4945 & 0.4965 & 0.4940 & 0.4933 \\
\hline Enterprise & 7 & 8 & 9 & 10 & 11 \\
\hline $\begin{array}{c}\text { approaching } \\
\text { degree }\end{array}$ & 0.4921 & 0.4907 & 0.4904 & 0.4863 & 0.4860 \\
\hline
\end{tabular}

On basis of tab 5, we can rank the quality credit scores of the 11 enterprises from high to low as follow:

\section{$1>4>2>3>5>6>7>8>9>10>11$}

In the ordinary course of quality credit evaluation, we rank the quality credit level just by the sum of all indicators, but when introduce the method of grey correlation and TOPSIS; we can get more exact result. According to tab 5, it is clearly showed that the quality credit level of the 11th enterprise is the lowest.

\section{Conclusions}

This paper combines the method of grey correlation with TOPSIS to evaluate the enterprise quality credit. Compared with the existing evaluation methods, it can not only evaluate the overall alternatives, but also reflect the differences between changing trend of alternatives and the ideal alternative, and it turns out to be an effective evaluation method.

\section{Acknowledgment}

We would like to express our gratitude to all those who have helped us during the writing of this paper. We also deeply appreciate the helpful review comments and suggestions by anonymous reviewers.

\section{References}

[1] Y. Sun, The industry enterprise quality credit evaluation establishment application in Shandong province. Shandong University, 2012. (In Chinese)

[2] L. Liu, Analytical hierarchy process in the enterprise quality credit evaluation system application. South China University of technology, 2010. (In Chinese)

[3] X. Zhu, Quality credit evaluation based on TOPSIS: Evidence from air-conditioning market in China. Procedia Computer Science, 2012(9):1256-1262. (In Chinese)

[4] W. Qian and Y. Dang, Based on the grey relation of fixed weight TOPSIS method and its application. System Engineering, 2008, 27(8):124-126. (In Chinese)

[5] S. Ding and Z. Wang, Evaluation effect of safety input-output for city-level power supply enterprise based on grey correlation degree improved TOPSIS. Water resources and power, 2013, 3(4):222-224. (In Chinese)

[6] H. Leng, Study on the Combination of the TOPSIS optimization and GREY relevancy in The Projects of Sichuan Agricultural Industrialization. Southwestern university of Finance and Economics, 2012. (In Chinese)

[7] Opinions On Strengthening the Supervision of Corporate Credit Quality General Administration of Quality Supervision, Inspection and Quarantine of the People's Republic of China, 2006. (In Chinese)

[8] L. Yanbin, Y. Xinyi, Risk Assessment on Photovoltaic Power Generation Project by Grey Correlation Analysis and TOPSIS Method. Power System Technology, 2013, 37(6):1514-1519.

[9] C. Zhao and Y. Liu, Evaluation for Survivable Networked System Based on Grey Correlation and Improved TOPSIS. JOURNAL OF NETWORKS, 2011, 6(10):1514-1520.

[10] G. Hui, S. Bifeng, Study on effectiveness evaluation of weapon systems based on grey relational analysis and TOPSIS. Journal of Systems Engineering and Electronics, 2009, 20(1):106-111.

[11] C. Hsu, An Application of Grey Relation TOPSIS to Evaluate Travel TV Program: A Case of Cambodia Tour Planning with the Theme of Dark Tourism. Advanced Science Letters, 2013(19):985-987. 